\title{
Pre-service primary teachers have a say on genericism in mathematics curriculum preparation
}

\begin{abstract}
Stephen Norton
Jeanne Maree Allen

The purpose of this paper is to report on a study that investigated pre-service teachers' perceptions about an attempt to prepare them to teach mathematics to primary aged children. Mixed methods were used to provide basic statistics data and to categorise and summarise qualitative data. Contextualised in an Australian initial teacher education program, the study first surveyed 447 first-year pre-service primary teachers to achieve insight into what they wanted to gain from their forthcoming mathematics curriculum courses. Qualitative responses were categorised and used to guide the development of tailored course interventions, which focused on attempting to ensure depth of school mathematics content knowledge and specific pedagogy associated with this mathematics. A second survey, administered through post-course evaluations $(n=261)$, suggests that pre-service teachers overwhelmingly valued the modelling of specific pedagogies and scaffolding of the teaching and learning of school mathematics concepts. The results have implications for the teaching of mathematics in initial teacher education programs, particularly in Australia and elsewhere where there is an increasing emphasis on pre-service teachers being classroom ready at graduation. This includes a deep and connected knowledge of the mathematics and range of pedagogies for the mathematics they will soon be certified to teach.
\end{abstract}

Keywords: pre-service mathematics teaching; initial teacher education; mathematics teachers; mathematics pedagogy

\section{Background}

In a recent analysis of Australian school student performance, Gonski et al. (2018) reported that:

Since $2000 \ldots$ academic performance has declined when compared to other

Organisation for Economic Co-operation and Development countries, suggesting

that Australian students and schools are not improving at the same rate and are

falling short of the full learning potential of which they are capable. (p. viii)

A similar message was reported by the Australian Government's Productivity Commission (2017), which raised concerns about school students' declining results and low levels of teacher effectiveness. In 2016, Masters (2016) also expressed concern about the declining capacity of Australian children to excel in mathematics at a time when such capability was increasingly needed for the growth of economic and social capital. As part of the focus on turning this situation around, Gonski et al. (2018) underscored the importance of maintaining "an unrelenting focus" (p. xv) on the rigour of the implementation of reforms proposed by the Teacher Education Ministerial Advisory Group in 2014 "to achieve the goal of raising the quality of our initial teacher preparation and improving the classroom readiness of graduate teachers" (p. xv). 
In this light, it is worth noting that there are a number of key factors that can be argued to contribute to the relative lack of excellence of Australian school students' results in international tests. In their summary of the literature on high-performing education systems (HPES), Deng and Gopinathan (2016) identified four critical enablers: teacher quality, school leadership, system characteristics and educational reform. Of interest in this paper is teacher quality, which Deng and Gopinathan concluded was ensured by highly selective recruitment and effective initial teacher education.

Concerns with respect to the effectiveness of teacher preparation have been raised by the Australian Mathematical Science Institute (O’Connor and Thomas 2019), who argue for the implementation of "much more explicit guidelines concerning the mathematics content knowledge needed for mathematics teachers" (p. 6). This argument is made on the grounds that "Australia is failing to provide enough teachers with the mathematical content knowledge they need to teach the classes before being assigned" (O’Connor and Thomas 2019, p. 9). The first author of the current paper, who has documented the level of pre-service primary teachers' mathematics content knowledge upon entry to mathematics curriculum courses (Author, 2012; 2016; 2017; 2018), echoes the concerns of O'Connor and Thomas (2019) and shows that many pre-service teachers struggle with upper school content, including division, fractions, proportional reasoning and early algebra, which represent the very content domains that primary students struggle to master.

To date, there has been limited research into what pre-service teachers value in terms of knowledge forms that might be developed in their mathematics curriculum courses; this paper provides empirical evidence that goes some way towards addressing this gap. As Deneen, Brown, Bond and Shroff (2013) noted, understanding pre-service teachers' perspectives of higher education reform is important, and students are "capable of accurately evaluating valuable educational experiences", with "strong positive correlations between academic achievement and student evaluations" (p. 442). Thus, the aims of the paper are as follows:

1) To document the knowledge forms of mathematics that pre-service primary teachers value at the commencement of a mathematics curriculum course, and

2) To document their response to attempts to meet these needs.

Insights drawn from these data will be discussed in the contexts of course and program structures. 


\section{Literature review}

\section{Genericism in teacher preparation}

Over 30 years ago, in relation to United States teacher preparation programs of the early 1980s, Shulman (1986) asked, "Where did the subject matter go? What happened to the content?" (p. 5). Shulman, a noted American educational psychologist, argued that teacher education programs were essentially organised around generic competencies including evaluation, cultural awareness and recognition of individual differences, understanding youth, management, educational policies, and instructional plans. More recently, the term "genericism" is often used in place of generic competencies, with commentators such as Beck and Young (2005) defining the concept as one that focuses on key skills, thinking skills, core skills, problem solving and teamwork. The underpinning assumption would appear to be that generic thinking skills can be taught and then transferred (to a significant degree) to specific subject domains. Bernstein (2000), who shared Shulman's (1986) concerns, argued that genericism or "generic modes of professional training" had come to dominate teacher education and were linked with trainability to meet market needs.

In his analysis of $20^{\text {th }}$-century teacher accreditation examinations, Shulman (1986, p. 5) observed that the critical factor in these examinations was relatively low-level demands on knowledge of content. Subsequent to his analysis of teacher preparation programs in the 1980s, he also claimed that "Although knowledge of the theories and methods of teaching is important, it plays a decidedly secondary role [to content knowledge]". More recently, other authors have shared this view (e.g., Ball, Thames and Phelps 2008; Bourke, Ryan and Lidstone 2013; Chapman 2015; Kotzee 2012; Muller 2000; Winch 2010; Young and Muller 2010). Beck and Young (2005) commented on "progressive de-specialisation of institutions of formal education and a growing diffuseness and/or emptiness of academic and pedagogic identities" (p. 192). Bourke et al. (2013) describe a "new professionalism" that has emerged since teacher preparation has become dominated by classroom management and understanding general theories of learning, arguing that this risks reducing teachers to "recipe following" with respect to specific mathematics pedagogy.

Sweller (2016) argues for the critical role of an expert in the subject domain to carefully structure learning. The goal of instruction becomes one of reducing unnecessary working memory load, which is highly restricted to facilitate the transfer of domain specific information into long-term memory, which is potentially vast (Sweller, 2016). According to cognitive load theorists (e.g., Kirschner, Sweller, 
and Clark 2006; Kirschner, Verschaffel, Star, and Dooren 2017; Tricot and Sweller 2014), planning and implementing instructional discourse is dependent upon the teacher/instructor having a deep understanding of the discipline and being able to communicate this clearly with minimal distracting stimuli. Importantly, the discipline is very fine grained. Further, "these topics [taught in educational and training institutions] require learners to acquire domain-specific rather than generic-cognitive knowledge" (Sweller 2016, p. 360). The importance of explicit guidance in classroom discourse has been accepted by general theorists who have assessed multiple data sources on the effectiveness of different teaching approaches (e.g., Hattie 2009; Hattie and Donoghue 2016).

\section{Teacher preparation in Australia}

The influence of genericism in Australian educational policy remains manifest. The Through Growth to Achievement report (Gonski et al. 2018, p. xii), for example, offers support for generic interpretation of standards: "Give more prominence to the acquisition of the general capabilities," such as, critical and creative thinking, personal and social capability. The Australian Professional Standards for Teachers (Australian Institute for Teaching and School Leadership [AITSL], 2017) state clearly that graduate teachers need to possess the requisite knowledge and skills to plan and manage learning programs for students. It is anticipated that graduate teachers will have an understanding of their subject(s)' curriculum content and teaching strategies, but the level of expertise is only vaguely stated. As stated by O'Connor and Thomas (2019, p. 7), “Generic and pedagogical skills are well defined by the Australian Institute for Teaching and School Leadership. Subject discipline skills are not.”

Across Australia, and consistent with AITSL (2017) recommendations, initial teacher education programs typically include courses in dimensions of learning, understanding diverse learners, contemporary influences in schooling, pedagogies for engaged learners, research-informed teaching, wellbeing, and so forth. In addition, primary teachers in the study institution typically undertake courses in subject domains including mathematics, science, history, geography, language development, science and technology, health and physical education, special needs, communication for teaching and learning, education and society and understanding lifelong learning.

It is not surprising then that in primary undergraduate programs at the institution in which the current study took place, the mathematics component now represents between $9 \%$ and $12 \%$ of total credits. The actual learning time for mathematics teaching can be minimal, down to a dozen or so hours 
of lectures and workshops with online support, to courses offered entirely online over truncated learning blocks of time.

Further, modes of assessment, including in mathematics curriculum courses, are dominated by take-home assignments that arguably draw on literacy and generic research skills rather than specific knowledge of mathematics and how to teach it (Author 2018). This results in pre-service teachers being able to pass mathematics curriculum courses on the basis of essays, lesson plans and take-home assignments. Tasks such as the construction of lesson plans, writing essays and completing selfreflections tend to assess generic literacy and academic competency rather than specific competency in mathematics content and pedagogy.

\section{A framework for categorising pre-service teachers' knowledge for teaching mathematics}

Shulman emphasised the importance of content domain or mathematical content knowledge (MCK) and pedagogical content knowledge (PCK) and made a distinction between the two. His understanding of PCK was that it includes knowledge such as what sequence/s of questions to ask when assisting school students to understand particular mathematics concepts. In this paper, we adopt the concept of mathematics pedagogical content knowledge (MPCK) as defined by Gess-Newsome (2013), with an emphasis upon: "purposefully blend[ing] content knowledge with attention to student learning and powerful instructional strategies" (p. 259). We also see considerable commonality with MPCK as theorised by Dohrmann, Kaiser, and Blomeke (2012) and, more recently, school-related content knowledge (Dreher, Lindmeier, Heinze, and Niemand 2018).

\section{Method}

Mixed methods were used to collect and analyse the data. Grounded theory methodology underpins the analysis of themes that emerged from the data. We started with questions and collected data, coded them, and collected more data in the anticipation that repeated ideas would become apparent. Descriptive statistics are used to describe summarised survey data collected at the commencement and end of the mathematics curriculum courses. Examples of pre-service teachers' comments are presented.

\section{Participants}

Three groups of primary pre-service teachers took part in the study. The first was a cohort of primary Graduate Diploma of Education students, all of whom had completed a degree, mostly in the 
humanities. These pre-service teaches were about to undertake their single 10-credit-point mathematics curriculum course before graduating (Cohort A, $n=72$ of which 70 were initially sampled). The other two groups comprised third-year Bachelor of Education Primary students, all of whom had successfully completed two mathematics curriculum courses and were either undertaking a final mathematics curriculum course (Cohorts B and C, $n=434$ of which 379 were initially sampled) or a mathematics curriculum elective (Cohorts D and E, $n=32$ of which 28 were initially sampled).

\section{Data collection techniques}

Pre-service teachers were surveyed at the start of their mathematics curriculum course. The survey questions were open ended, thus allowing useful concepts to emerge from the data (Cohen, Manion, and Morrison 2018). The qualitative data reported in this paper are related to responses to two prompts: What do you think is the most important feature of quality mathematics teaching? and What do you most want from this course? Given the similarity between individual responses to both prompts (many participants duplicated their answers), responses to the first prompt have not been included in this paper. The survey was voluntary (Ethics protocol number EDN/34/14/HREC).

At the end of the course there was a second survey which was anonymous, voluntary, and conducted online as part of the university's standard Student Evaluation of Course (SEC). Surveying at the end of the course in an online manner largely explains the reduction in response rates. Two additional questions were added to the standard Likert-style response SEC: The focus on mathematical content knowledge in this course assisted my learning, and The focus on explicit mathematics teaching methods in this course assisted my learning and responses to these are reported in this paper. The inclusion of these questions followed the analysis of participants' initial responses in the first year of the study. The students also provided extensive written comments that supported the Likert responses $(5=$ strongly agree to $1=$ strongly disagree). A sample of these comments is documented to help articulate the reasons why the preservice teachers responded as they did in the anonymous survey. The open-ended nature of the prompts What did you find particularly good about this course? and How could this course be improved? stimulated the potential for a diversity of themes to emerge. It is recognised that these prompts are rather leading, but unfortunately, SEC prompts offer limited modification. Nonetheless, Deneen et al. (2013) have reported that SEC metrics can be reliable and valid and can yield insightful data (providing the sample is representative). Table 1 provides details about participant response numbers. 
Table 1. Participants: Numbers of Pre-Service Teachers who Contributed to this Study through Completion of Pre-Course Survey and Post-Course Survey

\begin{tabular}{lll}
\hline Cohort and number initially enrolled & Pre-course & Post-course \\
\hline A-2014 Primary graduate $n=72$ & $70(97 \%)^{*}$ & $38(53 \%)$ \\
B-2015 Primary undergraduate $n=224$ & $179(80 \%)$ & $94(42 \%)$ \\
C-2015 Primary undergraduate $n=210$ & $200(95 \%)$ & $110(52 \%)$ \\
D-2015 Primary undergraduate elective $n=18$ & $15(83 \%)$ & $11(61 \%)$ \\
E-2016 Primary undergraduate elective $n=14$ & $13(93 \%)$ & $8(57 \%)$ \\
Total of Primary pre-service teachers $n=$ & $477(82 \%)$ & $261(49 \%)$ \\
\hline
\end{tabular}

*The percentage of the total who responded to SEC is listed

\section{Description of the interventions}

Over the life of the study the mode of course delivery was altered. Cohort A, for example, was afforded a 2-hour lecture followed by a 3-hour workshop over 8 weeks (40 hours of in-person teaching modelling). The delivery of the intervention to Cohort E consisted of a 2-hour lecture followed by a 2hour workshop over 7 weeks (28 hours of in-person teaching and modelling).

The mathematics content at the heart of the interventions differed minimally, with primary preservice courses focused on teaching primary content including: numeration and computation of whole numbers and fractions, early algebra, introduction to proportional reasoning, and primary geometry. The level of mathematics was at the requisite level for pre-service teachers who were soon to be certified to teach. In terms of theorising the organisation of the content and subsequent analysis of the pre-service teachers' responses, we have drawn on the thinking of cognitive load theorists cited above. The course structure was essentially teacher centred with the first-named author attempting to model effective teaching of MCK and, through that process, to model effective MPCK. By way of attempting to illustrate the nature of the intervention, a sample of the assessment items included in a summative exam is provided, with associated commentary, in Table 2. 
Table 2. Sample of Assessment Items

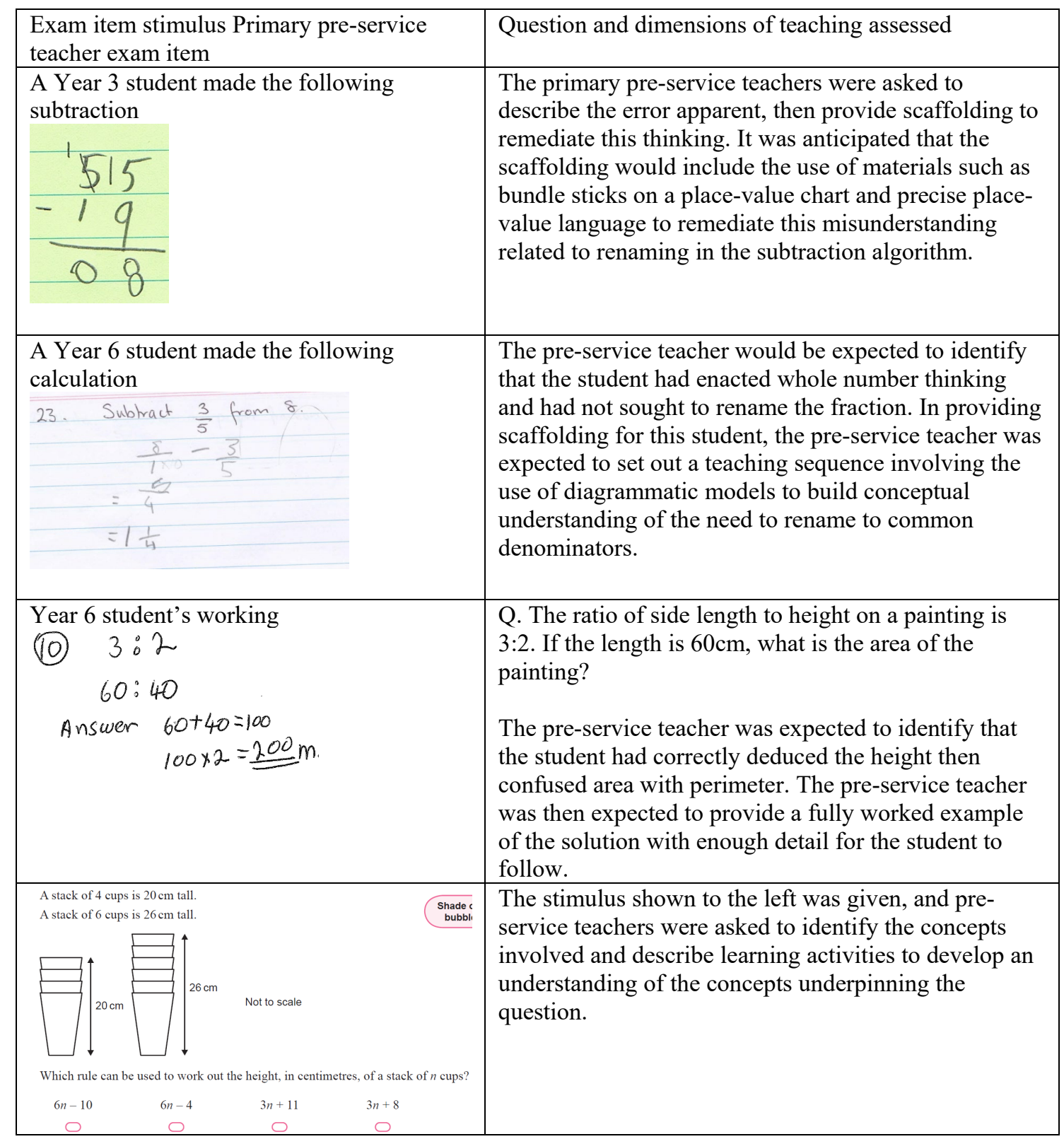

The rationale behind including the types of assessment items illustrated in Table 2 is that these items demonstrate pre-service teachers' attempts to teach the content at the same time as illustrating their domain-specific pedagogy. Pre-service teachers could not gain high marks on the exam without a deep and connected knowledge of the specific mathematics and the detailed pedagogy associated with scaffolding the content learning. MPCK includes the effective representations of mathematical concepts, including appropriate use of language, and the capacity to interpret students' thinking from their written computations. Pre-service teachers were only assessed on content and pedagogy that was explicitly taught during the interventions. For each exam, there were between 15 and 20 questions similar in structure to 
those presented above. The examinations were closed book and calculators were not permitted. The rationale for this is that the lecturer wished to assess pre-service teachers' levels of memory, understanding, and fluency in mathematics problem solving and MPCK. The Australian mathematics curriculum is clear that school students similarly need to demonstrate these competencies (Australian Curriculum, Assessment and Reporting Authority [ACARA], 2018).

\section{Analysis}

Participants' written responses to the survey prompt What do you most want from this course? were read several times in order to discern themes. Consistent with grounded theory methodology, open coding enabled initial categories or themes to emerge from the data (Cresswell 2005). Eight themes emerged and were subsequently classified as essentially associated with knowledge related to tools, techniques, and ingredients. Some comments did not fit into these descriptors, so a fourth category was developed: general social/psychological factors. It is proposed that this last category underpins Professional Standard 1 (Know students and how they learn - physical, social and intellectual development) and Standard 4 (Create and maintain supportive learning environments); for brevity this category has been named social/psychological. This last classification can reasonably be considered generic.

Some comments related to more than one theme and some participants did not record a response. The comment following pertains to two themes: "Make it interesting. Relevant to the real world. How to teach the content." This statement was coded as ability to make mathematics engaging, and MPCK. The comment: "How to teach a subject I was afraid of myself," was coded as MPCK and enhanced teacher confidence (social/psychological). The response: "To brush up on my content and learn how to teach it" was coded MCK and MPCK. The examples in Table 3 illustrate the coding in more detail; they are listed in order of relative frequency. Frequency was consistent across the different cohorts and this justified amalgamating the data. 
Table 3 Major Themes in Response to What do you most want from this course?

\begin{tabular}{ll}
\hline Theme & Example comment \\
\hline MPCK & Teaching strategies for mathematics ... Maths language and steps \\
& $\ldots$ How to break a complex maths problem into simple steps ... \\
MCK & Learn the content; understanding of the maths I will be teaching ... \\
& Refresh my understanding of maths ... improve my maths ... \\
Enhanced teacher confidence & Be confident in knowing what I am teaching ... Confidence to teach \\
& $\ldots$. Being more confident that I know the maths. \\
Make mathematics engaging & Making mathematics fun ... Making it relevant to the real world ... \\
Diagnose thinking & Learn how to find out what is stopping their success ... Diagnose \\
Behaviour management & their errors in mathematics. \\
Develop student confidence & I want to be able to develop in children more confidence than I had \\
\hline
\end{tabular}

The capability to diagnose students' mathematical thinking is directly related to a deep knowledge of the mathematics content. Similarly, a teacher's capacity to engage students in conceptual thinking about mathematics is dependent upon the teacher's depth of knowledge of content and pedagogy. The same coding processes were applied to SEC responses where dominant themes emerged from the data at the end of the intervention.

\section{Results}

The results that help to answer the two research questions are presented as summaries of responses to the questions posed at the commencement and end of the course.

\section{Pre-course and post-course survey}

Pre-service teachers' responses to the prompt What do you most want from this course? were coded into eight themes according to the descriptors outlined in the methods section and are summarised in Table 4. 
Table 4. Major Themes in Response to What do you most want from this course?

\begin{tabular}{ll}
\hline Theme & $\begin{array}{l}\text { Primary (Total percentage } \\
\text { of } n=570 \text { comments) }\end{array}$ \\
\hline MPCK & $225(39 \%)$ \\
MCK & $179(31 \%)$ \\
Teacher confidence & $76(13 \%)$ \\
Make mathematics engaging & $35(6 \%)$ \\
Diagnose student errors & $37(6 \%)$ \\
Student confidence & $12(2 \%)$ \\
Know students & $5(.8 \%)$ \\
Behaviour management & $1(0.2 \%)$
\end{tabular}

Rounding accounts for the fact that these percentages do not add to exactly $100 \%$. In each coding process about $5 \%$ of comments could not be classified into the trends that emerged and were put aside.

The data in Table 4 indicate that a desire for specific mathematics pedagogy and depth of content knowledge accounted for $70 \%$ of all primary participants' responses. Teacher confidence accounted for $13 \%$ of the comments, and this was frequently linked to levels of MCK; for example, "I want to know more maths than the kids." The remaining comments were grouped under the category social/psychological and are essentially generic transferable capability (student confidence, know students, behaviour management). It needs to be recalled that numerous other courses in the program had a focus on developing social/psychological attributes.

\section{Post-course survey results (SEC)}

As with the pre-intervention survey, the post-intervention responses are summarised according to the frequency of response to the two prompts related to content and pedagogy and the open-ended SEC responses were classified into themes whose frequency is reported (see Table 5). Direct quotes are added to provide clarity.

Table 5 Pre-service Teachers' SEC Responses to Key Questions by Cohort.

\begin{tabular}{lll}
\hline Cohort (\% response rate) & $\begin{array}{l}\text { Mathematical } \\
\text { content focus } \\
(\mathrm{MCK}) / 5\end{array}$ & $\begin{array}{l}\text { Explicit mathematics } \\
\text { teaching methods } \\
(\mathrm{MPCK}) / 5\end{array}$ \\
\hline A-2014 Primary graduate $n=72(1$ campus-52\%) & 4.6 & 4.6 \\
B-2015 Primary undergraduate $n=224(39 \% ; 43 \% ; 57 \%)$ & $3.3: 2.4: 3.6$ & $3.3: 2.6: 3.5$ \\
C-2015 Primary undergraduate $n=220(45 \% ; 42 \% ; 63 \%)$ & $4: 8: 4.8: 4.8$ & $4.8: 4.7: 4.7$ \\
D-2015 Primary undergraduate elective $n=18(61 \%)$ & 4.9 & 4.8 \\
E-2016 Primary undergraduate elective $n=14(57 \%)$ & 5.0 & 5.0 \\
\hline
\end{tabular}


Since 5 represents strong agreement with the statements and 4 represents agreement, there is little doubt that almost all the pre-service teachers who responded to the SEC strongly endorsed the focus of the course on MCK and MPCK. The nuances of a desire for MCK and MPCK are illustrated in the different ways in which participants expressed what they considered was valuable for their future practice as teachers of mathematics.

I truly believe this is one of the only subjects that has made me felt qualified to be a teacher ... the knowledge I gained will make me the best maths teacher I can be.

The course covered all the mathematics concepts from early years to junior secondary and gave an in-depth explanation to teach each concept in a learner friendly way.

I have brushed up on my own mathematics skills and also learned how to teach maths. I now feel more confident teaching mathematics than any other subject.

I loved that we were taught exactly what we needed to know to teach maths well.

This gave me the clearest idea on HOW to teach students. I really feel like I could walk straight into a classroom and know what to do.

It was taught how we should teach. I learned the exact techniques and language that should be used in mathematics classes.

I believe that this is one of the only courses that can easily be transferred to the classroom.

Several participants made comparisons with the way earlier or other curriculum courses were focused:

I learned content in this course instead of generic teaching methods.

The course was engaging and practical. No unnecessary literature reviews, we learned how to teach maths!!!

The earlier mathematics curriculum courses were more about theory, this one focused on how to actually teach it.

Almost all the comments associated with the SEC prompt What did you find particularly good about this course? were classified into six themes as illustrated in Table 6 and below. 
Table 6 Major Themes in Response to What did you find particularly good about this course?

\begin{tabular}{ll}
\hline Theme & (Total percentage of $n=379$ comments) \\
\hline MPCK & $134(35 \%)$ \\
MCK & $91(24 \%)$ \\
Personal (social/psychological interactions) & $32(8 \%)$ \\
Engagement factor & $18(5 \%)$ \\
Resource quality/availability & $78(21 \%)$ \\
Well organised & $26(7 \%)$
\end{tabular}

Rounding accounts for the fact that these percentages do not add to exactly $100 \%$.

In terms of how the course could be improved most comments fell into eight themes, four of which accounted for 70\% of all comments: (1) More time needed: e.g., "This course needed to be run over a longer semester"; (2) Timetable issues: e.g., "Having the workshop and the lecture on the same day was too much! ... It is too hard to get to workshops if you have a day job ...”; (3) More support: e.g., "I needed more practice questions ... I needed more support to understand ...”; (4) Assessment-related issues: e.g., "It would have been good to have had more practice exams ... we needed our assignment marks back before the exam"; "the exam was too hard ...”; (5) Technology: e.g., "the workshops should have been recorded ... a printed book would have been good ..."; (6) Personal: e.g. ,"the lecturer could have cared more for us ...”; (7) Organisation: e.g., "they should not change the exam date"; and (8) Focus: e.g., "I disagree with the focus of the course, I can learn the maths in my own time when I need to".

Table 7 Major Themes in Response to How could this course be improved?

\begin{tabular}{ll}
\hline Theme & Primary (Total percentage of $n=226$ comments) \\
& \\
\hline More time & $76(34 \%)$ \\
Timetable issues & $22(10 \%)$ \\
More support & $24(11 \%)$ \\
Assessment clarity & $48(21 \%)$ \\
Technology related & $15(7 \%)$ \\
Personal comments related to teaching staff & $15(7 \%)$ \\
Organisation factors & $16(7 \%)$ \\
Focus of the course & $10(4 \%)$ \\
\hline
\end{tabular}


The data in Table 7 indicate that primary pre-service teachers were particularly concerned with rushing the course and feeling in need of greater learning support. Greater clarity in assessment, including more prompt return of feedback, was a substantial recommendation.

It is insightful to examine some of the comments from Cohort B, such as below:

This course would have been fine if I had learnt more content in previous maths courses. I felt I was just beginning to learn some of this content this Year. I hadn't touched this stuff since high school.

There was not enough time to properly understand the content/implementation alongside all of our other university stuff and lives.

Clearly, the lecturer (first named author) had misjudged the preparedness of this cohort to understand and learn how to teach upper primary mathematics. This correlated with approximately $30 \%$ fail rate on the $50 \%$ closed-book examination described above.

A student in Cohort B (least favourable cohort SEC) made the following anonymous comment:

This course will receive a lot of criticism for its rigour. It needs to be rigorous, in fact it is too soft to pass at $50 \%$ and conceded pass is ridiculous. Literacy and numeracy is education's core business. The only problem with this course is that it came too late in the degree and 8 weeks is too short. Expand it and make it harder to pass. Do not water it down. Australia will not be competitive in our region if we are being consistently outdone in maths. The university must take responsibility, have a vision and stand for it. I want my degree to be worth something!

\section{Discussion}

Bourke et al. (2013), Beck and Young (2005) and Bernstein (2000) have argued that the effect of professional standards such as the Australian Professional Standards for Teachers (AITSL 2017) upon tertiary teaching has been to diminish the voice of teachers and teaching academics to the detriment of quality, and to the hollowing out of discipline knowledge due to an emphasis on generic competencies. This concern has recently been supported by O'Connor and Thomas (2019). Phan (2014) also noted that pre-service teachers' voices ought to be considered more often as a consideration in enacting educational reform. Pre-service teachers in this study had undertaken at least 12 years of their own study of mathematics and most of them had seen mathematics teaching in practice while on school-based placement as part of their teacher preparation programs, thus it is legitimate to describe them as informed.

In response to the first research aim: To document the knowledge forms primary mathematics preservice teachers value at the commencement of a curriculum course, it is evident that most participants in this study wanted to deepen their content knowledge and specific mathematics-related pedagogy. As one pre-service teacher commented, "I want to understand the maths so I do not feel stupid on practicum". Domain-specific MCK and MPCK accounted for $70 \%$ of requests among participants. Desire to enhance 
social/psychological capacity in themselves or in their students accounted for about $11 \%$ of all comments. Almost all the social/psychological comments were related to participants desiring greater confidence, arguably a variable dependent upon their knowledge of MCK and MPCK.

The post-intervention data suggested that the pre-service teachers valued the opportunity to enhance their MCK and MPCK; in other words, the knowledge forms that theorists have stated are paramount for the teaching of mathematics (Shulman 1986, and, more recently, e.g., Hattie 2009). In effect, the data suggest that the pre-service teachers highly valued the forms of learning support that cognitive load theorists recommend (e.g., Chen, Kalyuga, and Sweller 2016; Kirschner et al. 2017; Sweller 2016; Tricot and Sweller 2014). Participants valued the delivery of the course consistent with Phan's (2014) description of teacher-centred learning; in other words, they endorsed a highly directive role for the teachers (e.g., Beck and Young 2005; Hattie 2009; Hattie and Donoghue 2016) as applied to their learning to teach.

In terms of how the courses could be improved, most participants cited the need for extra time and better timetabling, course sequencing issues, and concerns about assessment clarity, difficulty and feedback; between $11 \%$ and $15 \%$ explicitly requested more learning support. A few commented on the contrast between the focus of this course and others, for example: "No unnecessary literature reviews, we learned how to teach maths!!!"

The pattern of very positive acceptance of the goals and delivery was not uniform across the cohorts. Cohort B did not fit this pattern: many of these students rejected the course outright and some were offended by the expectations of the lecturer that they could master upper primary and lower secondary mathematics in the timeframes allocated. There is an important lesson that can be learned from Cohort B, and that is that the structuring of mathematics curriculum courses needs to take account of the starting knowledge and not demand progress that might be considered unreasonable by those participating. To overlook this consideration risks a negative reaction from pre-service teachers that potentially impacts on their self-efficacy.

Earlier in this paper, it was noted that there is a prevalence of genericism in teacher preparation in many initial teacher education programs (e.g., Beck and Young 2005; Bourke et al. 2013). It is argued here that this emphasis on genericism in its various manifestations has resulted in the fragmenting of teacher preparation programs, a feature recently acknowledged by O'Connor and Thomas (2019). The results reported in this paper suggest that there is an awareness by pre-service teachers that rebalancing in program 
structure may be warranted. This is evidenced in their desire for more time to develop their MCK and MPCK and in comments that indicated that some of them felt that aspects of genericism were overemphasised in the program.

\section{Conclusion}

The data presented in this paper are relevant to the structuring of teacher education programs, particularly in those instances where generalist programs advocating generic modes of thinking over reducing timeframes are implemented. Of course, this would only be relevant if there was evidence that many primary pre-service teachers had a shallow understanding of the discipline of mathematics prior to the completion of their teacher preparation courses. The first author has documented that this is the case in some instances (Author 2012; 2016; 2017; 2018). Thus, the data support the implementation of a set of standards in addition to the generic ones articulated by AITSL (2017). The new set of standards would be discipline focused on “discipline knowledge” (O’Connor and Thomas 2019). Thus, there is merit in considering adjusting intended course outcomes, supported by matching assessment that encourages the development of relevant knowledge. As reported as part of the "holy trinity" of Kirschner et al. (2017, p. 638), a deep knowledge of the domain is paramount for the professional growth of pre-service teachers. The implication is that general pedagogical knowledge or didactical knowledge can be developed across generically orientated curriculum courses, but at some point, content knowledge needs to be attended to and, in this study, pre-service teachers expressed a desire to learn the necessary content at the same time as learning the specific pedagogy.

Readers might consider that the data reported in this paper have relevance only to this institution and these cohorts. It needs to be noted, however, that the entrance protocols and program structures for preparing pre-service teachers are relatively similar across Australia. The commonality of program structures and the certification processes enacted by state accreditation bodies that use the AITSL (2017) standards as a basis for accreditation approval moderate this risk.

Given the fall in Australian school students' mathematical achievement since the 1990s (O'Connor and Thomas 2019), it is worth considering all variables and data sources and it is well recognised that the perspectives provided by pre-service teachers are important. Going forward, there are various options that can be explored, including employment of specialist mathematics teachers in primary school with commensurate specialisation in mathematics teacher preparation. 


\section{References}

Author $(2012 ; 2016 ; 2017 ; 2018)$

Australian Curriculum, Assessment and Reporting Authority (ACARA). (2018). Australian Curriculum: Mathematics. Retrieved from http://v7-.australiancurriculum.edu.au/mathematics/curriculum/f10? layout=2\#page $=1$.

Australian Government, Productivity Commission. (2017). Inquiry Report No 84: Shifting the Dial, 5 Year Productivity Review. Canberra: Commonwealth of Australia.

https://www.pc.gov.au/inquiries/completed/productivity-review/report/productivity-review.pdf. Accessed 18 January 2018.

Australian Institute for Teaching and School Leadership (AITSL). (2017). Australian Professional Standards for Teachers. https://www.aitsl.edu.au/teach/standards, Accessed 18 January 2018.

Ball, D., Thames, M., \& Phelps, G. (2008). Content knowledge for teaching: What makes it special? Journal of Teacher Education, 59, 389-407.

Beck, J., \& Young, M. (2005). The assault on the professions and the restructuring of professional Identities: A Bernsteinian analysis. British Journal of Sociology of Education, 26(2), 183-197.

Bernstein, B. (2000). Pedagogy, symbolic control and identity (Rev. ed.). Lanham, Boulder, New York, Oxford: Rowan \& Littlefield Publishers, Inc.

Bourke, T., Ryan, M., \& Lidstone, J. (2013). Reflexive professionalism: Reclaiming the voice of authority in shaping the discourse of educational policy. Asia-Pacific Journal of Teacher Education. https://www.tandfonline.com/doi/abs/10.1080/1359866X.2013.838619. Accessed 25 March 2018.

Chapman, O. (2015). Understanding and supporting teachers' knowledge for teaching. Journal of Mathematics Teacher Education, 18, 101-103.

Chen, O., Kalyuga, S., \& Sweller, J. (2016). Relations between the worked example and generation effects on immediate and delayed tests. Learning and Instruction, 45, 20-30.

Cohen, L., Manion, L., \& Morrison, K. (2018). Research methods in education (8th ed.). Abingdon, NY: Routledge.

Cresswell, J. (2005). Educational research: Planning, conducting and evaluating quantitative and qualitative research. $\mathrm{NJ}$ : Pearson.

Deneen, C., Brown, G., Bond, T., \& Shroff, R. (2013). Understanding outcome-based education changes in teacher education: Evaluation of a new instrument with preliminary findings. Asia-Pacific Journal of Teacher Education, 41(4), 411-456.

Deng, Z., \& Gopinathan, S. (2016). PISA and high-performing education systems: Explaining Singapore's educational success. Comparative Education, 52(4), 1-43.

Dohrmann, M., Kaiser, G., \& Blomeke, S. (2012). The conceptualisation of mathematics competencies in the international teacher education study TEDS-M. ZDM. Mathematics Education, 44(3), 325340 .

Dreher, A., Lindermeier, A., Heinze, A., \& Niemand, C. (2018). What kind of content knowledge do secondary mathematics teachers need? Journal fur Mathematik-Didaktik, 39(2), 319-341. https://link.springer.com/article/10.1007\%2Fs13138-018-0127-2. Accessed 4 December 2018. 
Gess-Newsome, J. (2013). Pedagogical content knowledge. In J. Hattie \& E. Anderman (Eds.), International guide to student achievement (pp. 257-259). New York: Routledge.

Gonski, D., Arcus, T., Boston, K., Gould, V., Johnson, W., O'Brien, L., et al. (2018). Through growth to achievement: The report of the review to achieve educational excellence in Australian schools. Canberra, ACT: Commonwealth of Australia.

Hattie, J. (2009). Visible learning: A synthesis of over 800 meta-analyses relating to achievement. London: Routledge.

Hattie, J., \& Donoghue, G. (2016). Learning strategies: A synthesis and conceptual model. npj Science of Learning, 1. http://www.nature.com/npjcilearn. Accessed 4 December 2018.

Kirschner, P., Sweller, J., \& Clark, R. (2006). Why minimal guidance during instruction does not work: An analysis of the failure of constructivist, discovery, problem-based, experiential, and inquirybased teaching. Educational Psychologist, 41(2), 75-86.

Kirschner, P., Verschaffel, L., Star, J \& Dooren, W. (2017). There is more variation within than across domains: An interview with Paul A. Kirschner about applying cognitive psychology-based instructional design principles in mathematics teaching and learning. Mathematics Education, $47,637-643$

Kotzee, B. (2012). Expertise, fluency and social realism about professional knowledge. Journal of Education and Work. http://www.tandfonline.com/doi/abs/10.1080/13639080.2012.738291. Accessed 25 March 2016.

Masters, G. (2016). Policy insights: Five challenges in Australian school education. https://research.acer.edu.au/cgi/viewcontent.cgi?article=1004\&context=policyinsights. Accessed 12 October 2018.

Muller, J. (2000). Reclaiming knowledge: Social theory, curriculum and education policy. London and New York: Routledge Falmer.

O’Connor, M., \& Thomas, J. (2019). Australian secondary mathematics teacher shortfalls: A deepening crisis. Australian Mathematical Sciences Institute. https://amsi.org.au/wpcontent/uploads/2019/05/amsi-occasional-paper-2.pdf. Accessed 13 August 2019.

Phan, L. H. (2014). The politics of naming: Critiquing "learner-centred" and "teacher as facilitator" in English language and humanities classrooms. Asia-Pacific Journal of Teacher Education, 42(4), (392-405).

Shulman, L. (1986). Those who understand: Knowledge growth in teaching. Educational Researcher, 15(2), 4-14.

Sweller, J. (2016). Working memory, long-term memory, and instructional design. Journal of Applied Research in Memory and Cognition, 5, 360-367.

Teacher Education Ministerial Advisory Group (TEMAG). (2014). Action now: Classroom ready teachers report. Canberra, ACT: Department of Education.

Tricot, A., \& Sweller, J. (2014). Domain-specific knowledge and why teaching generic skills does not work. Educational Psychology Review, 26, 265-283.

Winch, C. (2010). Dimensions of expertise. London: Continuum. 
Young, M., \& Muller, J. (2010). Three educational scenarios for the future. European Journal of Education, 45(1), 11-27. 